\title{
Análisis
}

\section{Digital asset management: la gestión de información multimedia en las organizaciones}

\author{
Por Àngels Jiménez
}

\begin{abstract}
Resumen: Se explica el concepto Digital asset management (DAM) o gestión de activos digitales, su significación en la creación de archivos multimedia, así como en la explotación y distribución del capital intelectual acumulado por numerosas organizaciones en forma de imágenes, gráficos, ilustraciones, ficheros de audio y vídeo, a lo largo de años de actividad. Se exponen las principales características y requisitos de las aplicaciones DAM. Se describe, a partir de la revisión de documentación obtenida en gran parte de los propios fabricantes, Cumulus, Teams, MediaBin y Documentum, cuatro de las soluciones mejor valoradas y más adoptadas internacionalmente. Finaliza con la enumeración y breve comentario de otras empresas y software de tecnología DAM.
\end{abstract}

Palabras clave: Digital asset management, Gestión de activos digitales, Gestión documental, Gestión de información multimedia, Archivos digi-

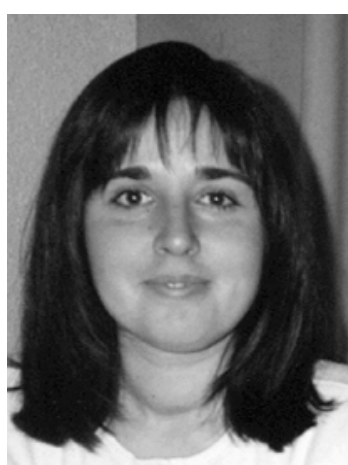
Àngels Jiménez, doctora en ciencias de la información, profesora de documentación informativa y de bibliografía de la Universidad Autónoma de Barcelona. Su línea de investigación se centra en la gestión de información en los medios de comunicación en internet.

tales multimedia, Tecnologías de la información.

\section{Title: DAM technologies: the management of multimedia information in organisations}

Abstract: This article explores the concept of Digital asset management (DAM) and its significance for creating multimedia archives, as well as for exploiting and distributing the intellectual capital accumulated over years of activity by numerous organisations - in the form of images, graphs, illustrations, audio and video files, etc.—. The main characteristics and requirements of DAM solutions are explained and a description is provided of four programs which are among the most highly evaluated and widely adopted internationally. The descriptions are based largely on a review of the documentation obtained from the creators of these applications: Cumulus, Teams, MediaBin, and Documentum. The article ends by listing — with a brief commentary-other companies working with DAM technology as well as other software packages.

Keywords: Digital asset management, Digital multimedia archives, Document management, Multimedia information management, Information technologies.

Jiménez, Àngels. "Digital asset management: la gestión de información multimedia en las organizaciones". En: El profesional de la información, 2003, noviembre-diciembre, v. 12, n. 6, pp. 452-461.

\section{Introducción}

Tradicionalmente la producción y uso de información audiovisual, sonora o gráfica se ha asociado a las industrias de la comunicación, editorial, ocio y entretenimiento. Sin embargo, la extensión social de internet, los nuevos modelos de negocio, así como el avance constante de la tecnología digital han favorecido que organizaciones de otros sectores, desde el alimentario al educativo pasando por el financiero, el sanitario o el de la automoción, perciban las posibilidades de la información multimedia para el desarrollo de actividades de comunicación, formación, promoción o ventas.

A lo largo de años de existencia numerosas instituciones y empresas (sobre todo multinacionales y grandes corporaciones) han acumulado, entre otros, documentos textuales, material fotográfico, vídeos, presentaciones de diapositivas, registros sonoros en soportes varios que constituyen un impor- tante capital intelectual que no siempre ha sido suficientemente valorado y explotado. En formato digital, y gestionado correctamente, ese capital puede ser de gran utilidad en departamentos de diseño de productos, publicidad y marketing, relaciones públicas, ventas, soporte al cliente, y abrir interesantes expectativas a la creación de nuevos servicios, mantenimiento de la imagen global de marca, formación del personal, etc. No obstante, para materializar esas expectativas son necesarias soluciones 
informáticas capaces de cubrir los complejos requerimientos que plantea la gestión de información electrónica y multimedia. Digital asset management es la tecnología desarrollada para dar respuesta a ello.

Lo que hay detrás de dicha tecnología no es en realidad un concepto nuevo, ya que está íntimamente relacionada y podría enmarcarse en lo que se entiende, en términos generales, como gestión electrónica de documentos (GED). Se trata más bien del fruto de años de investigación y avance que han dado lugar a la progresiva superación de las barreras técnicas que planteaba el tratamiento automatizado y sistemático de las tipologías documentales antes mencionadas (vídeo, audio, gráficos, imágenes, ilustraciones, logos, etc.). De hecho, los primeros pasos del Digital asset management se remontan a los inicios de la década de los años 90. En ese momento las agencias de publicidad, los medios de comunicación y otras organizaciones con la necesidad común de manejar e integrar en sus trabajos creativos material audiovisual empiezan a reclamar soluciones informáticas que les faciliten su labor. Si bien entonces el desarrollo de las primeras bases de datos multimedia contribuyó a paliar algunas de las necesidades planteadas, aún fue necesario esperar hasta finales de esa década e inicios del nuevo siglo para contar con verdaderos sistemas multimedia capaces de gestionar de forma integrada información de naturaleza diversa (textual, audiovisual, páginas web) y en multiplicidad de formatos (html, xml, pdf, jpeg, mp3, wav, mpeg, etc.).

Con la popularización de internet, numerosas empresas de los más diversos sectores han ampliado sus estrategias de negocio y puesto en marcha iniciativas de comercio electrónico. En este tipo de proyectos, los activos digitales jue- gan un papel determinante. Por ejemplo, de su uso inteligente en la elaboración de catálogos u otros materiales publicitarios en línea, dependerá en gran medida que el público internauta se anime o no a adquirir un producto, contratar un servicio o realizar transacciones comerciales a través de la Red. En definitiva, el desarrollo del comercio electrónico ha evidenciado aún más la necesidad de contar con aplicaciones que faciliten la gestión de activos digitales y la plantea en ámbitos de actividad en los que quizá, hasta entonces, no había sido percibida.

\section{¿Qué es Digital asset management (DAM)?}

Esta expresión, junto con media asset management (MAM), digital media management (DMM), rich media management $(R M M)$ y digital asset warehousing (DAW) se utiliza para designar lo que se conoce como gestión de activos digitales. Aunque la terminología no está fijada, DAM parece ser la que tiende a imponerse, de ahí que sea la utilizada en el presente artículo.

\section{«La gestión de acti- vos digitales se defi- ne como la actividad orientada a facilitar la creación, captura, ca- talogación, recupera- ción, exportación, transformación y dis- tribución de dichos activos a través de canales diversos»}

Por digital asset $\mathrm{o}$ activo digital (ésta es la traducción más extendida, aunque algunos autores también utilizan el término "valor digital') debe entenderse cualquier ítem de conocimiento, ya sea textual o de otra naturaleza, en formato de dígitos o bits, que constituye un valor para quien lo posee, porque puede reutilizarlo para crear otros, venderlo o publicitarlo. Un activo se concibe también como el conjunto formado por un contenido digital más la información asociada al mismo que sirve para su identificación, localización y control (metadatos, enlaces, datos adicionales sobre la localización, derechos y permisos de uso).

Partiendo de esta idea, la gestión de activos digitales se definiría como la actividad orientada a facilitar la creación, captura, catalogación, recuperación, exportación, transformación y distribución de dichos activos a través de canales diversos: internet, medios impresos, radio, televisión, telefonía móvil, PDAs, PCs. Hoy en día, esta gestión es posible gracias a los Digital asset managers, un tipo de software cuyo objetivo es facilitar la organización sistemática de contenidos digitales, el control y seguimiento de su uso, así como su explotación en procesos creativos relacionados con las nuevas formas de comunicación y comercio surgidas en el contexto de la sociedad de la información. Cabe destacar que dichos programas ponen un énfasis especial en lo que a reutilización y explotación de activos se refiere. Proporcionan utilidades que permiten al usuario editar y transformar, desde el propio sistema, documentos previamente almacenados (cualquiera que sea su naturaleza) e insertarlos con facilidad, y en el formato preciso, en los procesos de trabajo donde sean requeridos. Gracias a estas herramientas se consiguen notables ventajas. Por ejemplo, las empresas pueden acortar notablemente el tiempo de puesta en el mercado de nuevos productos, ya que los materiales relacionados con la promoción de los mismos son elaborados con mayor rapidez y en los formatos adecuados para su difusión por múltiples canales.

Las aplicaciones $D A M$ se caracterizan por integrar un conjunto 
de tecnologías que, coordinadas entre sí, hacen posible una gestión eficaz de los contenidos digitales, lo que para muchas organizaciones se traduce en ahorro de tiempo y dinero, así como en la consecución de beneficios no tangibles pero igualmente relevantes. Diversas empresas de análisis han señalado dos cuestiones significativas. Por un lado, que el tiempo de trabajo dedicado por los profesionales a la búsqueda de información ronda, en muchas compañías, el 15\%. Por otro, que en un alto porcentaje, los activos digitales empleados para crear nuevos documentos, son más rediseñados (por haberse perdido o deteriorado los previamente existentes) que reutilizados. Estos datos ponen de manifiesto un problema crítico para muchas organizaciones: la reducción del tiempo dedicado por los trabajadores a labores verdaderamente creativas. Los gestores de activos digitales aportan ventajas en este sentido; sin embargo, no son las únicas. De ahí que otras entidades como universidades, centros de investigación, bibliotecas, archivos o museos, no tan condicionadas por imperativos económicos y comerciales, puedan también obtener un notable provecho de estos sistemas.

Desde que la empresa de investigación Gistics identificara en 1993 el incipiente mercado de la gestión de activos digitales (Moon, 2003b), no ha dejado de señalar el dinamismo del sector. Sus cifras se barajan ya en millones de US\$ (se calcula que las ventas superarán los 4.000 millones en 2004) y su nivel de crecimiento anual se sitúa en un $60 \%$, lo que pone de manifiesto, por un lado, la existencia de una clara demanda social de las utilidades proporcionadas por los sistemas DAM y, por otro, la disposición de las organizaciones a invertir en esta tecnología.

\section{Características de las aplicaciones de gestión de activos digitales}

En su mayoría, los productos existentes en el mercado ofrecen las siguientes prestaciones, que deben entenderse también como requerimientos deseables:

\section{Características generales.}

-Arquitectura: cliente/servidor, cliente web o incluso ambas.

- Variedad de plataformas: las más habituales suelen ser Windows NT, 2000, XP, Sun y Linux, entre otras.

- Capacidad de integración: el sistema $D A M$ formará parte de la infraestructura de la empresa, de ahí que su arquitectura deba ser adaptable al contexto de uso. Sus componentes y funcionamiento deben poder soportar otros sistemas y procesos presentes en la organización y tener la capacidad de interactuar con ellos. Es importante también que sea personalizable, por lo que en general cuentan con APIs (Application programmer's interface) que facilitan la programación adaptada a entornos determinados de trabajo.

\section{«La diversidad de usuarios reflejada en las descripciones de los programas de- muestra la capacidad de adaptación de la tecnología DAM a di- ferentes entornos de trabajo»}

-Apoyado en estándares: para que el grado de interoperabilidad con otros sistemas (de la propia organización, socios, clientes, proveedores) sea óptimo, la mayoría de los programas trabajan con estándares abiertos xml, de comunicación, desarrollo y metadatos. De este modo se garantiza que los activos sean fácilmente accesibles.
—Escalabilidad: capacidad para crecer en paralelo al ritmo de transformación de la propia organización. Será un requerimiento indispensable, incluso cuando el volumen de los activos a gestionar aumente de forma exponencial. En la actualidad las necesidades de las empresas son cambiantes y las soluciones para responder a ellas aparecen en el mercado con rapidez. Un sistema escalable evitará el estancamiento y permitirá a la organización seguir siendo competitiva mediante la incorporación de recursos adecuados cuando las condiciones varíen.

-Facilidad para el trabajo en colaboración: uno de los mayores retos para las organizaciones es el control de versiones de documentos o flujos de trabajo cuando diferentes personas, ajenas o no a la empresa, participan en la elaboración $\mathrm{y}$, por lo tanto, disponen de capacidad para modificarlos y manipularlos. Tener la certeza de cuál es la última versión actualizada parece ser un problema superado con el uso de sistemas DAM. Según afirman los propios creadores, las aplicaciones están provistas de funciones específicas para el control de versiones que facilitan el trabajo compartido.

\section{Características de la ges- tión documental.}

- Soporte de activos digitales varios: los sistemas ofrecen funcionalidades específicas para gestionar la gama de materiales posibles (textos, fotografías, logos, gráficos, ficheros de audio y vídeo, páginas web, ficheros xml, radiografías, presentaciones PowerPoint, etc.). Estas prestaciones incluyen, por ejemplo, la captura y digitalización, indexación, tratamiento documental, control de uso y navegación.

- Herramientas para la adecuada descripción y catalogación de los activos: la identificación y 
recuperación de los materiales contenidos en el archivo es posible, en general, gracias a su descripción mediante metadatos (informaciones referidas a los propios datos y asociadas a ellos, como por ejemplo: formato del archivo, autor, palabras clave, derechos y limitaciones de uso, elementos relacionados con la captación de una imagen, etc.). Suele afirmarse que el valor de un activo digital, sus posibilidades de reutilización y explotación, dependen de su nivel de accesibilidad y éste, a su vez, de la exhaustividad con la que el activo haya sido descrito. Por ello es importante que el sistema ofrezca la posibilidad de adecuar los metadatos a la naturaleza de los diferentes activos. Sólo así se garantizará su correcta identificación y posterior recuperación.

Los metadatos sirven también para indexar los activos a partir de diferentes criterios, aunque cabe señalar que los problemas tradicionales asociados a la indización de documentos no textuales no son superados por los sistemas DAM. Sigue manteniéndose la necesidad de efectuar una indización humana porque las tecnologías de reconocimiento de voz o minutado de vídeos a partir de lo que en ellos se emite de forma oral, si bien han aportado algunas ventajas, no permiten pensar todavía en una indexación automática equiparable a la intelectual. La mayoría de programas permiten además clasificar los activos de forma jerárquica, utilizando descriptores controlados previamente definidos.

-Buen sistema de almacenamiento: aunque existen en el mercado soluciones para la gestión de activos específicos como por ejemplo, Video logger de Virage o Screening room de Convera, para vídeo, las aplicaciones $D A M$ alcanzan su mayor grado de complejidad y sofisticación cuando se orientan a la creación de bases de

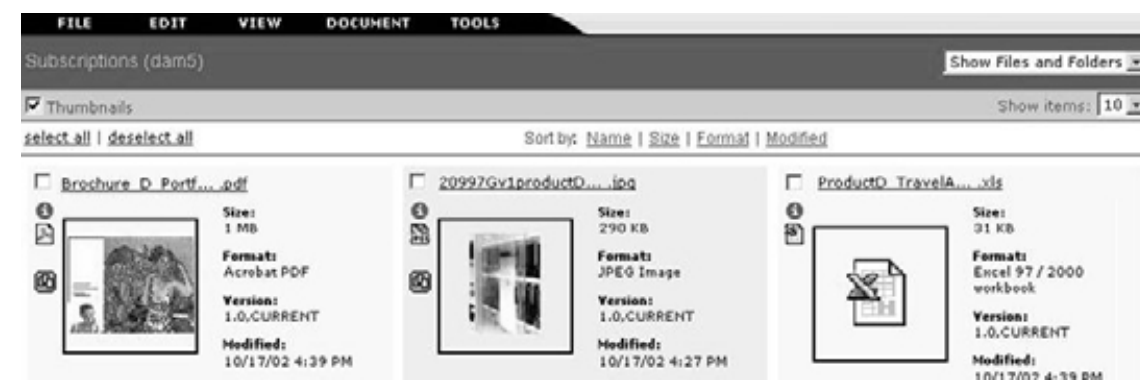

Figura 1. Ejemplo de thumbnails en Documentum. Fuente: Documentum-España

datos multimedia. Éstas pueden fundamentarse en la existencia de un archivo común en el que se integran contenidos de naturaleza diversa, o bien en la localización de los activos a partir de su ubicación original. Es viable un repositorio único gracias a que los gestores de activos digitales pueden trabajar con estructuras diferentes de datos y adecuarlas, mediante una codificación única (a través de xml, por ejemplo) para su correcto almacenamiento. El mayor o menor grado de estructuración de los documentos determinará las modificaciones que deberán experimentar para poder ser guardados y recuperados en el archivo común. Cuando no existe un repositorio único, el acceso a los originales se efectúa desde un catálogo que contiene las descripciones de cada uno de los activos. Los sistemas que funcionan de esta forma detectan cualquier cambio de ubicación de los documentos que realice el usuario, y pueden actualizar de forma automática el enlace que sirve como punto de acceso a los mismos.

-Facilidad para la recuperación: la descripción de los activos mediante metadatos permite efectuar búsquedas a partir de un catálogo cuyo contenido son las informaciones que los describen. Este sistema de recuperación resulta mucho más versátil y ofrece mayores posibilidades que el basado en la búsqueda por nombre de archivo, tamaño o fecha de creación, que, si bien puede ser útil cuando los documentos son pocos, resulta ineficaz cuando su número es ele- vado. La recuperación a través de metadatos reduce además la sobrecarga de las redes, evitando la transferencia innecesaria de ficheros que no sean los estrictamente requeridos.

Como en otras bases de datos, los sistemas DAM permiten el uso de elementos propios de los lenguajes de interrogación: operadores booleanos, de proximidad, truncamiento. Algunos incluso la búsqueda de imágenes a partir de características visuales como el color o la textura. Existen también modelos que utilizan redes semánticas que expanden las búsquedas mediante sinónimos y asociaciones de significados. En los programas donde es posible categorizar los recursos a partir de taxonomías la navegación constituye un sistema de recuperación complementario.

—Utilidades de visualización: muchas veces resulta difícil reconocer, entre los resultados de una búsqueda, cuál es el documento que se necesita porque tendemos a asignar nombres casi idénticos a archivos de contenido similar (foto1, foto2, foto3) lo que nos obliga a abrirlos en la mayoría de casos. Cuando se trata de materiales multimedia, esta comprobación puede hacer perder bastante tiempo. La mayoría de los gestores de activos digitales cuenta con elementos de previsualización como parte de los metadatos. Éstos se conocen en inglés como thumbnails. Se trata de imágenes reducidas de los documentos que permiten reconocerlos con facilidad sin necesidad de abrirlos o descargarlos (figura 1). 
-Difusión multicanal: para una distribución cross-media de los activos (a través de internet, medios impresos, radio, televisión, teléfonos móviles, PDAs, pcs) las soluciones existentes cuentan con funcionalidades que compatibilizan la información con los estándares y requerimientos de cada canal; es el caso de internet, con html o navegadores, por ejemplo. Esto es así porque los sistemas DAM pueden efectuar la conversión de formatos con facilidad y en tiempo real.

- Control y seguridad: una de las razones que impulsan a las organizaciones a invertir en la creación de un archivo multimedia es la voluntad de rentabilizar sus activos digitales, bien sea a través del ahorro de tiempo de sus trabajadores, que incluso desde sedes muy distantes geográficamente podrán acceder y reutilizar con facilidad un vasto capital intelectual, o bien, mediante su comercialización. A esta voluntad se añade la de proteger las inversiones hechas por algunas empresas en dichos activos. Gran parte de ellos suelen ser materiales procedentes de campañas publicitarias, de marketing y diseños digitales relacionados con el establecimiento de imágenes globales de marca. Estas razones justifican la preocupación de muchas

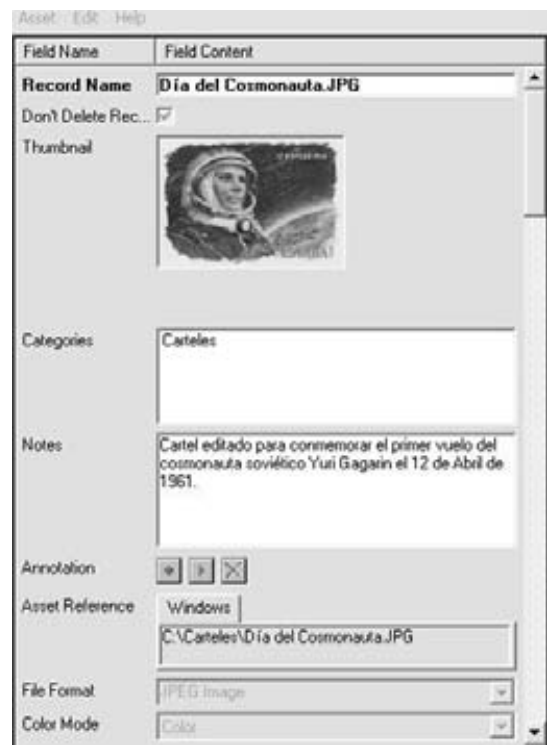

Figura 2. Fragmento de la interfaz de catalogación de Cumulus. Fuente: Canto organizaciones por garantizar la seguridad en el uso de estos documentos. Conscientes de ello, los creadores de aplicaciones DAM han dotado a sus productos de herramientas de control del uso de documentos y de gestión de autorizaciones. Con ellas se puede limitar el acceso de personas o grupos de usuarios y determinar opciones de lectura y/o escritura para cada uno de los activos. Así mismo es posible saber quién lo ha utilizado, cuándo y dónde.

\section{La oferta del mercado del software de gestión de activos digitales}

En un informe de Gistics publicado en 2002 se señalaba la existencia, en el panorama internacional, de 616 proveedores de tecnologías DAM (Moon, 2003a). Este hecho dificulta la tarea de identificar y valorar cuáles son las aplicaciones de mayor calidad. No obstante, en este apartado se describen de forma somera algunos de los principales productos que han sido seleccionados a partir de los siguientes criterios: valoración positiva por parte de analistas expertos de publicaciones especializadas, prestigio de los galardones recibidos dentro de la industria del software, número y naturaleza de las organizaciones en las que han sido adoptados y grado de liderazgo dentro del mercado de este tipo de aplicaciones. Es necesario señalar que a causa de las dificultades que plantea la observación del funcionamiento de los programas una vez implementados dentro de las organizaciones, la información que se ofrece a continuación está basada en informes de expertos, artículos de prensa especializada y material procedente de las propias compañías (fichas técnicas, versiones de demostración, visitas guiadas) por lo que habrá que considerar algunos de los datos aportados en su justa medida:
1. Cumulus: es un producto de la empresa Canto, compañía fundada en el año 1990 que posee sedes en Alemania, Francia, Japón y EUA. La primera edición se lanzó al mercado en 1992, lo que hace que el programa cuente con una larga trayectoria que le ha permitido mejorar y extenderse en sus consecutivas ediciones (en la actualidad se encuentra en la 5.5) (figura 2).

http://www.canto.com

Está disponible en versión monousuario, trabajo en grupo y empresa (en la sede web de Canto puede consultarse una comparativa muy detallada de las prestaciones de cada una). Sus precios son: 99,95 US\$ (monousuario); 995 US\$ la de trabajo en grupo para Mac OS y Windows y 1.995 US\$ para Unix, Linux, Irix y Solaris. El precio de la versión para empresas se establece en función de las necesidades de la misma y el tipo de instalación que deba realizarse.

Entre sus clientes se encuentran: Adidas, Apple, Bayer, Dow Jones, McDonald's, McGraw-Hill, Harvard University, Libray of Congress, Los Angeles times y Wall Street journal. Cumulus se distribuye en España a través de: EPS Electronic Publ. Systems (Madrid).

http://www.eps.es

2. Teams es una plataforma diseñada por la norteamericana Artesia Technologies, con oficinas en EUA, Reino Unido y más de seis años de experiencia en el desarrollo de tecnologías DAM. Se trata de un sistema abierto, construido en Java, SQL, Corba y xml (SOM, XSL, Smil y Smpte), del que destaca especialmente su capacidad para la gestión de vídeo gracias a la integración de Video Logger (uno de los mejores gestores existentes en el mercado para este tipo de documentos).

Se define como una solución orientada a grandes corporaciones. 
Entre sus usuarios se encuentran: Getty Images, AOL Time Warner Book Group, Campbell's Soup, Channel 4 UK, Fox Filmed Entertainment, General Motors, Sony Music, U. S. Dep. of Education, etc. Se trata de un producto que por sus capacidades es muy apreciado en los sectores de la comunicación y el entretenimiento, aunque éstos no son los únicos. De hecho, más de 120 marcas de todo el mundo, y de las más variadas actividades, lo utilizan.

http://www.artesia.com

El precio de la aplicación es elevado (a partir de 100.000 US\$). Por ejemplo, Emap, el tercer grupo editor de revistas de Francia, optó por Teams a finales de 2000 lo que le supuso, según Sébastien Chelin, el responsable del proyecto, una inversión en tecnología de 380.000 EUR, de los cuáles 152.000 se destinaron a dos servidores Sun y el resto a licencias de Teams y Oracle para los 25 primeros usuarios de Emap star, el más importante de los seis centros de actividad multimedia en los que el grupo editor ha organizado sus publicaciones (Archivos multimedia, 2002, p. 28). La oficina de ventas para Europa se encuentra en: 40 Holborn Viaduct, London, EC1N 2PB, Reino Unido.

3. Mediabin: la norteamericana MediaBin Inc. nacida en 1987, fue una de las empresas pioneras en el sector de los activos digitales. Recientemente Interwoven, especializada en la gestión de contenidos empresariales, la ha absorbido y ha integrado el ya consolidado $\mathrm{Me}$ diaBin asset manager a su plataforma (Interwoven 5). El Asset manager es un programa orientado a los profesionales de la publicidad y el marketing así como al comercio electrónico. Incorporado a la aplicación de Interwoven, enriquece las prestaciones que éste ofrecía al Enterprise content management $(E C M)$. De él se destacan su fácil implementación, el trabajo con estándares como xml, su capacidad de integración con otros sistemas y la creación de previsualizaciones de documentos en video streaming.

\section{http://www.interwoven.com}

Entre los usuarios de MediaBin asset manager están Reebok, Crayola, Samsonite, etc., y entre los aproximadamente mil clientes de Interwoven se encuentran 8 de las 10 mayores empresas del mundo. La dirección de la compañía en España es: Edificio Puerta de las $\mathrm{Na}$ ciones, Ribera del Loira, $463^{\text {a }}$ planta, Campo de Las Naciones, 28042 Madrid, tel.: +34-915030 123.

En la tabla 1 (pág. 458) se muestran las características de los tres programas.

4. Content server, Documentum media services y Documentum digital asset manager son productos de la empresa del mismo nombre. Fue fundada en EUA en 1990 y está especializada en la gestión de contenidos empresariales (sector genérico en el que se integran la gestión documental, de contenidos web y activos digitales). Cuenta con más de 30 sedes en todo el mundo y su producto líder es $D o$ cumentum, una plataforma integral que comenzó su andadura hace algunos años como gestor documental. Con la popularización de internet la plataforma se extendió a la gestión de contenidos web y en 2002, tras la compra de Bulldog Group por parte de Documentum en 2001, fue dotada de herramientas DAM de tecnología Bulldog. Éstas son: Content server, Documentum media services y Documentum digital asset manager.

Entre los clientes de Documentum se encuentran: Ericsson, Nokia, Vodafone, Japan Airlines, Master Card, Pepsi, Volkswagen $A G$, Renault, L'Oreal BMW, FBI,
Library of Congress, Banco de España, Mapfre, etc.

La oficina en España se encuentra en: Documentum software Ltd., Torre Europa, Paseo de la Castellana, 95 - 15A, Madrid 28046.

http://www.documentum-es.com/

El precio de la plataforma depende del tipo de instalación.

Usadas de forma complementaria, las extensiones $D A M$ de $D o$ cumentum aportan la práctica totalidad de funciones y utilidades requeridas por la gestión de activos multimedia. Las principales características de estas soluciones son:

-Plataformas: Windows NT Server 4.0 y 2000, Solaris, AIX 4.3, HP-UX.

- Soporte de bases de datos: Oracle 8i, Sybase 11, Microsoft SQL Server 7 y 2000, IBM DB2.

-Soporte de navegadores: Netscape e Internet explorer.

a. Content server: permite el almacenamiento y gestión de todo tipo de documentos (html, xml, gráficos y multimedia, así como los tradicionales creados con software de escritorio). Dirige el archivo y controla tanto el contenido como los procesos. Genera un repositorio global de arquitectura basada en estándares y fácilmente integrable a otras fuentes de contenidos. La aplicación posee una alta capacidad para el manejo de grandes volúmenes de información y el acceso simultáneo e ilimitado de usuarios. Dispone también de potentes herramientas para prevenir el uso de los documentos por personas carentes de autorización.

b. Documentum media services: extensión que ofrece capacidades avanzadas para la gestión integral de contenidos multimedia. Las más relevantes son: extracción automática de datos para la descripción de activos, creación de thumbnails, conversión de docu- 
mentos a diferentes formatos, modificación y edición de imágenes sin necesidad de trabajar desde programas gráficos; capacidad para visualizar vídeos o escuchar ficheros audio mientras están siendo descargados desde internet al ordenador (streaming); posibilidad de gestión de nuevos formatos o tipos de activos que aparezcan en el futuro (figura 3 ).

c. Digital asset manager: interfaz basada en un navegador que, complementada con Documentum Media Services, permite la automatización, control y disponibilidad de imágenes, audio y vídeo. La aplicación facilita:

-Previsualizar secuencias de imágenes representativas del contenido de vídeos a baja resolución.

- Compartir recursos entre Mac y PC (cuando un usuario de PC deba acceder a un recurso creado con Mac, éste será despojado de los elementos que le dificultarían el acceso, mientras que esos mismos elementos seguirán permaneciendo intactos para los usuarios de $M a c$ ).

- Buscar y consultar presentaciones PowerPoint sin tener que descargarlas y abrirlas. Asimismo, seleccionar y ensamblar diapositivas a partir de representaciones en miniatura de las mismas.

- Convertir archivos a cualquier formato reconocido por $\mathrm{Do}$ cumentum media services.

\begin{tabular}{|c|c|c|c|}
\hline & Mediabin & Cumulus & Teams 4.4 \\
\hline Plataformas & ASP, Mac, Windows & Mac, Windows, Solaris, Irix, Linux & $\begin{array}{l}\text { Mac OS9, Solaris, Windows NTy } \\
\text { XP }\end{array}$ \\
\hline Escalabilidad & Alta & Alta & Total \\
\hline Personalización & Alta & Muv alta & Completa \\
\hline Acceso internet a contenidos & $\mathrm{Si}$ & Sí & Sí \\
\hline Formatos gestionables & $\begin{array}{l}\text { Numerosos: fotos, gráficas de } \\
\text { anuncios, Power Point, } \\
\text { presentaciones gráficas, pdf, vídeo, } \\
\text { archivos de audio, etc. }\end{array}$ & $\begin{array}{l}\text { Más de 130: 3D Metafile, Frame, } \\
\text { Freehand, gif, jifi, jpeg, Kodak } \\
\text { DCS , MacPaint, Movie } \\
\text { QuickTime, Page Maker, pdf, } \\
\text { Photoshop, Power Point, } \\
\text { QuarkXpress , Riff, tiff, Scitex, } \\
\text { Pics , zip. } \\
\end{array}$ & $\begin{array}{l}\text { Más de 200. Destaca } \\
\text { especialmente por su capacidad } \\
\text { para la gestión de vídeo gracias a } \\
\text { la integración de Video Logger. }\end{array}$ \\
\hline \multirow{4}{*}{ Arquite ctura } & Tres elementos clave: & Modular integrada por 3 elementos: & $\begin{array}{l}\text { - Application interface: browser } \\
\text { construido en J2EE y JSP que se } \\
\text { inteqra al Business loqic. }\end{array}$ \\
\hline & - Repository : archivo & $\begin{array}{l}\text { - Metadata Server : responsable de } \\
\text { la gestión de metadatos. }\end{array}$ & $\begin{array}{l}\text { - Business services : servicios } \\
\text { enlazados entre si mediante una } \\
\text { aplicación middleware Corba } \\
\text { que dirige el tráfico de la red } \\
\text { facilitando la comunicación. }\end{array}$ \\
\hline & $\begin{array}{l}\text { - Imaging task controller: responsable } \\
\text { del proceso de datos, resuelve las } \\
\text { peticiones de los clientes. }\end{array}$ & $\begin{array}{l}\text { - Processor Server : encargado de } \\
\text { la gestión de los activos. }\end{array}$ & - Rich Media Repository. \\
\hline & $\begin{array}{l}\text { - Imaging primitives : elementos para } \\
\text { el procesado de imágenes (codificado, } \\
\text { decodificado...). Cada primitive se } \\
\text { encarga de una única tarea. }\end{array}$ & $\begin{array}{l}\text { - AssetServer : procesael acceso a } \\
\text { los documentos originales. }\end{array}$ & \\
\hline \multirow{2}{*}{ Almacenamiento } & - Repositorio único. & $\begin{array}{l}\text { - No archiva por defecto los activos } \\
\text { en un repositorio centralizado, } \\
\text { aunque puede hacerlo. }\end{array}$ & - Respositorio único. \\
\hline & - Base de datos SQL u Oracle. & $\begin{array}{l}\text { - Los documentos permanecen en } \\
\text { su ubicación original. El sistema } \\
\text { genera el punto de acceso. }\end{array}$ & $\begin{array}{l}\text { - Los originales se almacenan en } \\
\text { un sistema jerárquico y } \\
\text { confiqurable de ficheros. }\end{array}$ \\
\hline \multirow[b]{2}{*}{ Metadatos } & - Campos ilimitados de metadatos. & $\begin{array}{l}\text { - Personalizables según las } \\
\text { necesidades del cliente. }\end{array}$ & $\begin{array}{l}\text { - Personalizables según las } \\
\text { necesidades del cliente. }\end{array}$ \\
\hline & $\begin{array}{l}\text { - Capacidad de captación automática } \\
\text { y } \\
\text { entradamanual. }\end{array}$ & $\begin{array}{l}\text { - Capacidad de captación } \\
\text { automática y entrada manual. }\end{array}$ & $\begin{array}{l}\text { - Capacidad de captación } \\
\text { automática y entrada manual. }\end{array}$ \\
\hline Control de vocabulario & Sí & $\begin{array}{l}\text { Permite asignar, como metadatos, } \\
\text { palabras clave predefinidas. }\end{array}$ & $\begin{array}{l}\text { Permite asignar, como metadatos, } \\
\text { palabras clave predefinidas y el } \\
\text { trabajo con tesauros. }\end{array}$ \\
\hline Sistema de clasificación & Sí & $\begin{array}{l}\text { Jerárquico de carpetas que } \\
\text { corresponden a categorías que } \\
\text { pueden ser personalizadas. }\end{array}$ & Sistema de carpetas. \\
\hline Sistema de recuperación & $\begin{array}{l}\text { Variadas: a partir de metadatos, } \\
\text { contenido de las imágenes, similitud } \\
\text { visual. }\end{array}$ & $\begin{array}{l}\text { Variada gama de opciones de } \\
\text { búsqueda incluida la navegación a } \\
\text { través de categorías. }\end{array}$ & $\begin{array}{l}\text { Variada gama de opciones de } \\
\text { búsqueda incluidala navegación a } \\
\text { través de categorías. }\end{array}$ \\
\hline \multirow[t]{2}{*}{ Previsualización de documentos } & $\begin{array}{l}\text { - Sí. } \\
\text { - Thumbnails : sí. }\end{array}$ & $\begin{array}{l}\text { - Sí. } \\
\text { - El abanico de ficheros que pueden } \\
\text { generar thumbnails es amplio } \\
\text { (jpeg, gif, eps, tiff, Adobe } \\
\text { Photoshop. QuickTime). }\end{array}$ & $\begin{array}{l}\text { - Si. } \\
\text { - Thumbnails : sí. }\end{array}$ \\
\hline & $\begin{array}{l}\text { - Puede generar streaming video } \\
\text { como previsualización. }\end{array}$ & & \\
\hline \multirow[t]{2}{*}{ Seguridad } & $\begin{array}{l}\text { - Si. } \\
\text { - Permite establecer perfiles de acceso } \\
\text { a documentos. }\end{array}$ & $\begin{array}{l}\text { - Sí. } \\
\text { - Permite establecer perfiles de } \\
\text { acceso a documentos. }\end{array}$ & $\begin{array}{l}\text { - Sí. } \\
\text { - Permite establecer perfiles de } \\
\text { acceso a documentos. }\end{array}$ \\
\hline & $\begin{array}{l}\text { - Control yseguimiento del uso de los } \\
\text { documentos. }\end{array}$ & $\begin{array}{l}\text { - Control y seguimiento del uso de } \\
\text { los documentos. }\end{array}$ & $\begin{array}{l}\text { - Control y seguimiento del uso de } \\
\text { los documentos. }\end{array}$ \\
\hline Control de versión & Sí & Sí & Sí \\
\hline Compatibilidad con of & Si & Sí & Sí \\
\hline
\end{tabular}

Tabla 1. Análisis comparativo de MediaBin, Cumulus y Teams. Fuente: Elaboración propia 
- Detectar automáticamente documentos streaming, ahorrando al usuario la descarga completa para su reproducción.

El programa cuenta además con algunas de las utilidades propias de los gestores de contenidos empresariales como por ejemplo flujos de trabajo o ciclos de vida, entre otras.

De los productos analizados, Cumulus, al ser el único con versiones monousuario y de grupo, resulta el más accesible para particulares o pequeñas organizaciones. Teams se orienta claramente a grandes corporaciones; Documentum y la plataforma de Interwoven están también en esa misma línea. Los tres constituyen buenos ejemplos de la convergencia tecnológica que se observa en el sector. De hecho, los dos son plataformas amplias de gestión de contenidos empresariales, en las que el sistema o módulo $D A M$ es parte integrante, lo cual no significa que no pueda funcionar de forma independiente y autónoma. Dado que los tres productos se encuentran entre los líderes del mercado, las diferencias no son muy significativas en lo que a gestión de activos multimedia se refiere. La más destacada corresponde quizá al modo como se almacenan los activos (repositorio único o permanencia en su ubicación original). La diversidad de usuarios reflejada en las descripciones de los programas demuestra la capacidad de adaptación de la tecnología $D A M$ a diferentes entornos de trabajo (medios de comunicación, agencias publicitarias, universidades, organismos oficiales, bibliotecas, empresas alimentarias, financieras, textiles, automoción). Gracias a las amplias posibilidades de personalización de estas aplicaciones, su adecuación a las necesidades de la mayoría de organizaciones está prácticamente garantizada, a diferencia de las soluciones ad hoc por las que optan algunas

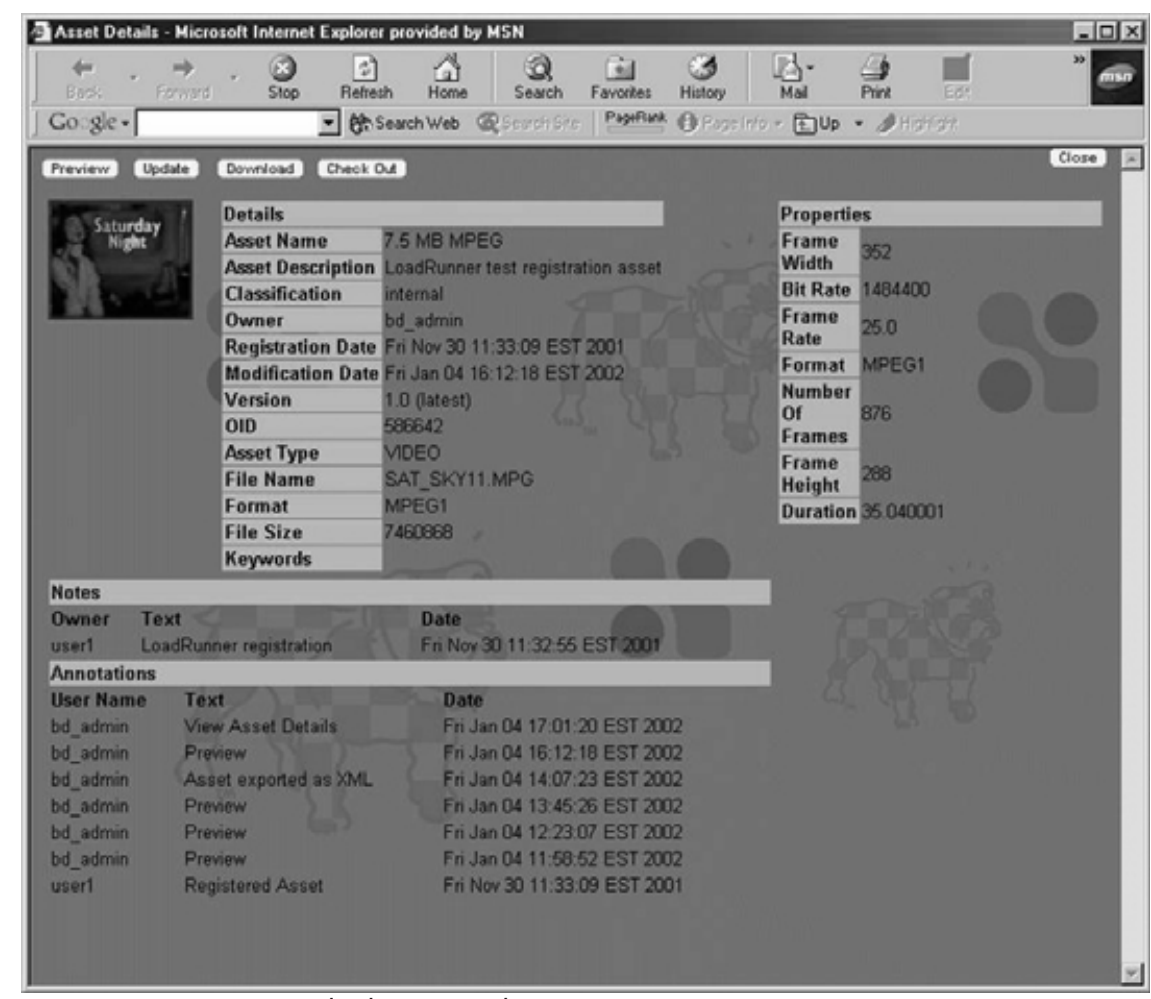

Figura 3. Ejemplo de registro de Documentum. Fuente: Documentum-España

empresas. Estas suelen resultar menos flexibles, interoperativas y escalables.

\section{Otras empresas y soluciones}

Como se indicó anteriormente, existen numerosos proveedores de tecnologías DAM. Como complemento a los programas descritos se mencionan a continuación otros, con el fin de ofrecer una visión más completa de las aplicaciones disponibles en el mercado:

- Convera: empresa surgida en el año 2000 gracias a la fusión de Excalibur technologies y la $\mathrm{Me}$ dia services division de Intel. Ofrece soluciones con potentes sistemas de recuperación, alguna de las cuales (Retrievalware, por ejemplo) utiliza técnicas de procesado de lenguaje y redes semánticas. Chicago tribune y De telegraaf se cuentan entre los usuarios de este sistema. Su software Screening room es quizás uno de los más conocidos gestores de vídeo junto a $\mathrm{Vi}$ deo logger.

http://www.convera.com
-Emotion comercializa ArchivePartner, CreativePartner y $\mathrm{Me}$ diaPartner. Del último destaca, al igual que en los productos de Convera, la utilización de redes semánticas para dar soporte a la recuperación.

http://www.emotion.com

- Alfa mosaic y Alfa mediaStore, de la compañía danesa Pine Tree Software, son distribuidos por la alemana Alfa Media Partner. http://www.alfa.de

Estas soluciones se orientan a medios de comunicación, principalmente a periódicos (están muy extendidas entre los alemanes, por ejemplo). Alfa mosaic sirve para la gestión de imágenes y Alfa mediaStore para la de texto, sonido, imagen y vídeo. Como base de datos para el almacenamiento utilizan Oracle.

http://www.pinetreesoftware.net

-Protec: con más de diez años de experiencia y sedes en Barcelona, Madrid y Lisboa, está especializada en la empresa informativa. En 1995 presentó Arcano, que se publicitaba como el primer archivo multimedia español para 


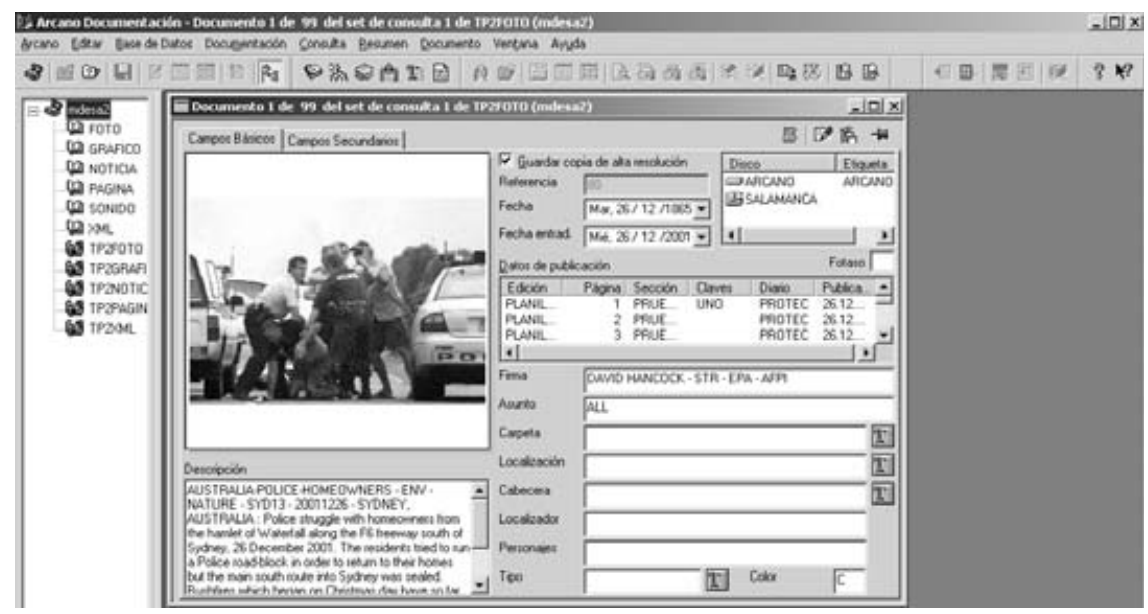

Figura 4. Visualización detallada de resultados de una consulta en Arcano. Fuente: Protec

periódicos y revistas, aunque no gestionaba documentos audiovisuales (figura 4). En el año 2000 comercializó Milennium cross media, un entorno amplio compuesto por tres elementos: publicidad, solución editorial y archivo digital. Como archivo digital utiliza Arcano, que en la actualidad gestiona texto, fotos, infografía y páginas html, aunque mediante una extensión puede incluir sonido. Entre los actuales proyectos de la empresa está el desarrollo de herramientas para el tratamiento de vídeo. En España son unas 50 las cabeceras que lo utilizan o lo han utilizado. Entre ellas se encuentran: El mundo, Diario de León, Sur, Diario de
Cádiz y las publicaciones del Grupo Voz.

http://www.protec.es

-OCS Technologies: grupo de empresas fundado en 1981 y con oficinas en Barcelona, Madrid y Miami.Comercializa OCS glob@l, al que define como un sistema gestor de documentación corporativa desarrollado en java. Como sistema de gestión y archivo digital, capaz de administrar documentos en papel, radiografías, microfichas, microfilm y vídeo comercializa OCS optic. La compañía cuenta entre sus socios con Convera y entre sus productos Excalibur.

http://www.ocstechnologies.com

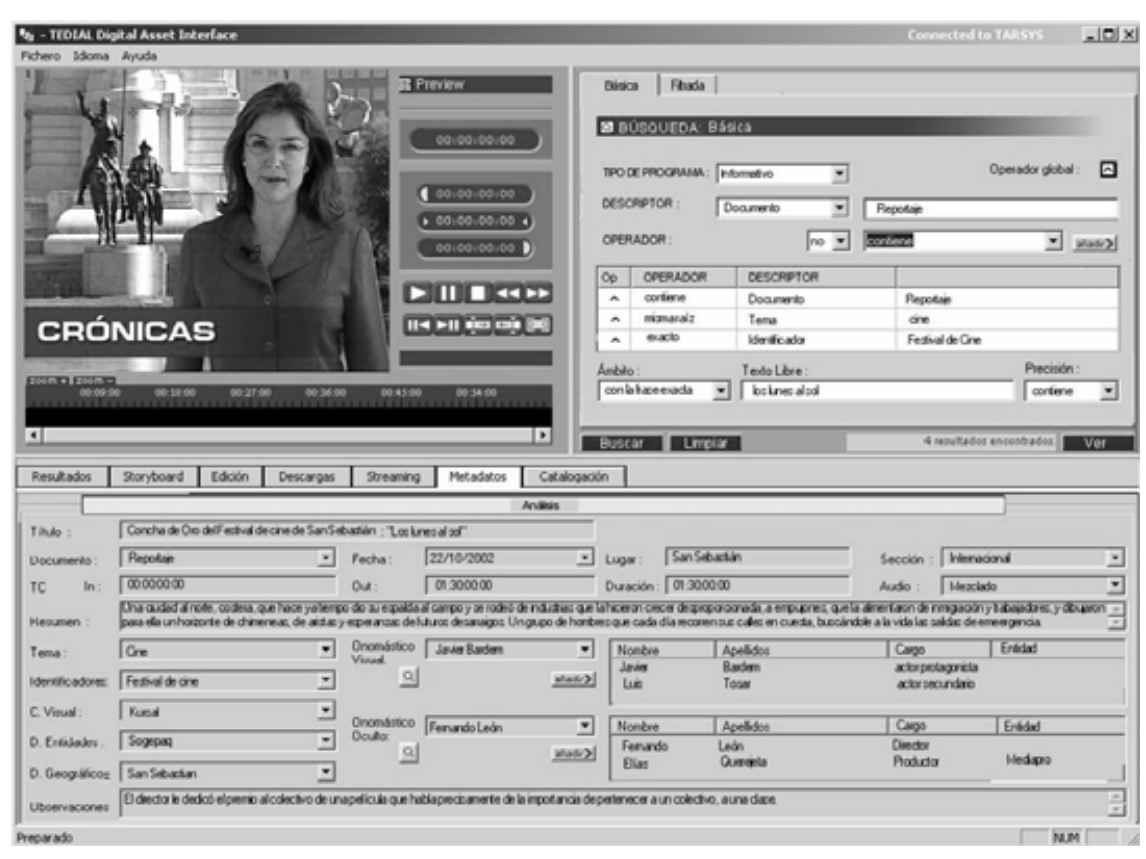

Figura 5. Ejemplo de registro y búsqueda básica en Tarsys. Fuente: Tedial
-Tedial: esta empresa, con sede en Málaga y especializada en sistemas de información audiovisual, aporta al mercado español Tedial, una interesante y completa solución para la producción, gestión y distribución de contenidos (figura 5). Su plataforma cuenta con varios módulos o aplicaciones entre las que figura TD Tarsys MAM un gestor de archivos multimedia. Éste puede trabajar con textos, imágenes, audio y vídeo en diferentes formatos (mpeg, Real Video, DVC Pro, Audio Mpeg Layer, pdf, etc.). Entre sus clientes se encuentran el Consell Català de l'Audiovisual, Ministerio de Justicia, Barcelona TV y Grupo Godó. http://www.tedial.com

\section{Conclusión}

Si se entiende la GED como un concepto genérico, la gestión de activos digitales podría inscribirse o incluso identificarse con ésta porque ambas se orientan a un mismo fin: el tratamiento sistemático de todo tipo de documentos en formato digital. Sin embargo, si se observan como tecnologías, los productos DAM presentan en la actualidad algunas características y utilidades que no siempre se dan o están tan desarrolladas en las aplicaciones de GED tradicionales (aunque las diferencias tienden a desaparecer). Tales características tienen que ver, sobre todo, con la relación entre usuarios del sistema y documentos almacenados en el mismo:

- Marcada orientación hacia la distribución y creación de contenidos: los DAM potencian más que otros sistemas la reutilización y distribución de los activos. Para ello cuentan con herramientas que facilitan considerablemente ambas tareas. Aunque son soluciones de gestión, almacenamiento y recuperación documental, no son únicamente eso. Pretenden ser instrumentos que sirvan además para la 
edición y creación de nuevos activos a partir de la reutilización de los preexistentes y sin necesidad de salir del propio entorno del sistema.

- Gran capacidad de conversión: otra de sus claves es el potencial para la transformación instantánea de activos a múltiples formatos, lo que favorece su exportación y difusión multicanal.

- Sofisticadas herramientas para la automatización de flujos de trabajo y seguridad en el uso de los documentos: control riguroso de las versiones de documentos en proceso de creación, redirección de los activos hacia sus siguientes destinatarios, control de los derechos de acceso y utilizaciones previas de los activos. Los programas además, pueden reflejar automáticamente cualquier cambio y hacerlo inmediatamente visible a toda la estructura de la organización.

—Facilidad de manejo: son programas concebidos para usuarios no expertos (por ejemplo, la entrada de documentos al sistema puede ser algo tan sencillo como arrastrar y soltar el ratón).

Existe una clara demanda del tipo de soluciones que aportan las tecnologías $D A M$, sobre todo por parte de profesionales o departamentos creativos. Esta demanda es consecuencia, por un lado, del alto grado de complejidad que supone la gestión de activos multimedia y, por otro, de la necesidad que tienen numerosas organizaciones de proteger las inversiones que realizan en dichos activos, así como de rentabilizarlos mediante su reutilización para la producción de nuevos trabajos (campañas publicitarias, mantenimiento de la imagen global de marca, comercialización, etc.).

Los beneficios que pueden proporcionar (mejora del trabajo en colaboración, aporte de tiempo a las tareas creativas, capitalización y protección de los activos, etc.) así como su contribución a las oportunidades de negocio que ofrece la distribución y comercialización de contenidos digitales, hacen presagiar que en un futuro inmediato serán numerosas las compañías e instituciones que invertirán en este tipo de sistemas. No obstante, cabe señalar que su implantación exige inversiones que no siempre están al alcance de cualquier organización.

En la actualidad existen diversas tecnologías (Content management, Document management, Digital asset management, Web content management) que las empresas adquieren a menudo por separado, para dar respuesta a sus diferentes necesidades. Sin embargo, todo parece apuntar que pronto se producirá un cambio significativo. El mercado muestra una clara tendencia a integrarlas en plataformas de gestión de contenidos empresariales (enterprise content management). La finalidad de esta convergencia es ofrecer al cliente una herramienta única que le permita la gestión integral de todos sus contenidos corporativos y contribuya a eliminar o reducir los costes derivados de la implementación de nuevos módulos de utilidades en sus sistemas. En este sentido Teams, Interwoven y Documentum constituyen claros ejemplos. Sin embargo, no son los únicos. Algunos de sus más inmediatos competidores se sitúan ya en la misma línea.

\section{Bibliografía}

“Archivos multimedia". En: Técnicas de prensa, 2002, febrero, pp. 17-31.
Artesia Technologies. "The essential characteristics of enterprise digital asset management". Consultado en: 12-06-03.

http://www.artesia.com/pdf/essential_EDAM.pdf

Canto. "Cumulus 5.5 why upgrade?". Consultado en: 12-06-03.

http://www.canto.com

CMS Spain: Centro de Información y recursos sobre IT para Content management, Gestión documental e Información en España. Consultado en: 29-05-03.

http://www.cms-spain.com

Digital Imaging Guide. Consultado: 28-05-03. http://www.dig-mar.com/Resources/ AProducts.html

Documentum. Consultado en: 02-06-03. http://www.documentum-es.com/products/ collateral/index.html

EC2@USC Digital Asset Solutions. Consultado en: 02-06-03.

http://www.ec2.edu/dccenter/dam/solutions.html

Econtent 100. Consultado en: 02-06-03.

http://www.econtentmag.com/EContent100/

Gistics. "Site resources DAM Market Report". Consultado en: 03-06-03.

http://www.gistics.com/site.taf? function $=q c s r \&$ pac_id $=m m 126 \&$ start $=1$

Lancie, $P$. de. "Refreshing media management: Coca-cola turns archives into assets". En: Econtent. Consultado: 28-05-03.

http://www.econtentmag.com/Articles/ArticleRe ader.aspx?ArticleID $=855$

McQuilken, Toni. "DAM! how do you define digital asset management?". En: Digital output magazine, 2003, June. Consultado en: 28-06-03. http://www.digitaloutput.net/back\%20edit/june 03/ss2.html

Moon, Michael [a]. "Announcing the Digital asset management market report", 09-02-2003. Consultado en: 03-06-03.

http ://www.gistics.com/site.taf? function $=q c d \& p$ ac_id $=m m 126 \&$ absrow $=1$

Moon, Michael [b]. "Dam report executive summary", 09-02-03. Consultado en: 03-06-03. http: $/ / w w w . g i s t i c s . c o m /$ site.taf? function $=q c d \& p$ ac_id $=m m 126 \&$ absrow $=2$

Àngels Jiménez, Área de documentación, Fac. de Ciencias de la información, Universidad Autónoma de Barcelona.

angels.jimenez@uab.es

\section{Nueva dirección de Swets Blackwell}

Las oficinas en España de la agencia de suscripciones Swets Blackwell (desde ahora Swets Information Services) se han trasladado a:

\author{
Nápoles 227, $2^{\mathrm{a}}$ planta \\ 08013 Barcelona \\ Tel.: +34-932081970 \\ Fax: $+34-932081971$
}

